\title{
Reflections at the end of the millennium
}

No-one could deny the enormous advances in the understanding of infectious diseases that have occurred in the recent past. In less than 150 years we have moved from near total ignorance of the causes of infection, the ways in which it spreads, and the effects that it has on the human body, to a situation in which most microbial disease is understood (at least at a superficial level) and prevention or cure of all but a few infective conditions can be achieved relatively simply - although scandalous inequalities in health care worldwide ensure that they are not.

A big breakthrough came, of course, with the establishment of the germ theory of disease through the pioneering work of Pasteur, Koch and their contemporaries in the second half of the 19th century. By the turn of the century, this Golden Age of microbiology had identified and loosely categorised most of the common pathogenic bacteria, fungi, protozoa and helminths, although the role of viruses remained to be elucidated. The first glimmerings of the therapeutic revolution were also beginning to appear, with an incipient realisation of the role of the immune system, the potential of protective vaccination (already foreshadowed by Jenner's work on cowpox) and the earliest indications that specific chemotherapy might extend beyond the use of quinine, mercury and a few herbal anthelminthics.

At the same time, improvements in public health were beginning to have a profound impact in many countries of the world. By the turn of the century in the UK, typhus had virtually disappeared, tuberculosis had started its long decline and the appallingly short lifeexpectancy, which had fallen to below 40 years in some parts of the country during the industrial revolution, was again on the increase [1].

None the less, at the end of the 19th century annual mortality, much of it caused by infection, was still around $2 \%$. Diseases such as diphtheria, measles, whooping cough, scarlet fever, puerperal fever, tuberculosis and infectious diarrhoea remained major killers in the UK and elsewhere. In some cases, notably mortality from childbed fever, little was to change until the advent of antibacterial agents [2].

What are the major milestones of the 20th century? Each of us could draw up their own list, but all would, I imagine, contain the events shown in the box.

\section{Some microbiological milestones of the 20th century \\ Triumphs \\ Tragedies \\ Prontosil (sulphanilamide) 1918 influenza pandemic \\ Penicillin \\ Antituberculosis agents \\ Vaccine development \\ Smallpox eradication \\ Failure to control: \\ malaria \\ tuberculosis \\ infant mortality}

On the plus side is the therapeutic revolution that began with Ehrlich's Salvarsan (1909); emerged as a true breakthrough with Domagk's Prontosil (sulphanilamide; 1932-1935); achieved its final triumph with Florey and Chain's development of Fleming's penicillin (1940-1941); and sealed its success with Waksman and Schatz's discovery of streptomycin (1943). A steep decline in mortality from infectious diseases has continued. In the USA, mortality from infectious diseases is estimated to have fallen steadily from 797 deaths $/ 100000$ population in 1900 to $36 / 100000$ in 1980, albeit with a transient increase during the influenza epidemic after the First World War [3]. The decline was halted by the HIV pandemic and, in fact, deaths from AIDS contributed to a rise in mortality from infectious disease in the USA during the 1980s. It then fell again to a level of 59 deaths/100000 in 1996 [3].

Much of the success in reducing deaths attributable to infection can be accounted for by continued improvements in nutrition, housing and environmental hygiene, although antimicrobial agents have had an important part to play [4]. Vaccination, culminating in the global eradication of smallpox in 1977 [5], has also had a profound impact. As the century draws to a close, polio and guinea-worm disease are also in line for eradication, while onchocerciasis and lymphatic filariasis are also being targeted for elimination [6].

The 20th century has also witnessed microbiological disasters: high on the list must be the influenza pandemic of 1918 , which is estimated to have killed at least 20 million people, and AIDS, which emerged in the 1980 s and continues to reap its grim harvest. These diseases are a potent reminder of the havoc that 
microbes, in particular viruses, can wreak without prior warning. Equally sobering is the failure to control, in much of the world, preventable and treatable infections: the unremitting toll of tuberculosis, malaria, cholera and many diseases of childhood - almost forgotten causes of premature death in the affluent west - is an indictment of our collective failure to bring social and scientific advances to the poor and underprivileged. Perhaps the most striking example of this failure is the continued high mortality from infectious diarrhoea among infants, much of which could be prevented by the provision of clean water and simple oral rehydration fluids [7].

What of the coming century? The future is an unknown country and my crystal ball is no better than the next man's in divining what might transpire. None the less, certain generalisations are possible. Infectious disease is not going to go away. Indeed, there is arguably as much, if not more, microbial disease now than at any time in history. In addition to the classic infectious diseases that continue unchecked in many of the less developed nations of the world, 'new' bacterial pathogens (Legionella pneumophila, Helicobacter pylori, Campylobacter jejuni, Borrelia burgdorferi, Escherichia coli O157), viruses (HIV, hepatitis C, E and $\mathrm{G}$, human herpesviruses 6 and 8 ) and protozoa (Cryptosporidium parvum, Cyclospora cayetanensis) - all discovered in the last quarter of the 20th century - add to the known microbial disease burden. Foodborne infection is at an all-time high and opportunist infection proliferates among the vulnerable beneficiaries of high-technology medicine in our hospitals. Despite the intensive effort being put into research on microbial pathogenicity, host response, epidemiology and control, we are still only scratching the surface in our understanding of these topics; to suggest otherwise is simple scientific arrogance.

The writing is on the wall for antimicrobial drug resistance, although the much trumpeted 'post-antimicrobial era' [8] is certainly still a long way away [9]. Most of the problems of resistance in the developed world are likely to remain in the forcing houses of high-dependency units of hospitals, in which multiresistant opportunist microbes find a fertile field in seriously ill patients. In the developing world, multiple drug resistance in organisms responsible for classic infectious diseases, such as malaria, tuberculosis, pneumonia, dysentery and typhoid fever, will continue to flourish so long as there is a failure to regulate effectively the manufacture, marketing and use of potent antimicrobial drugs [10].

The pharmaceutical industry promises us that advanced techniques of genomics, molecular modelling and combinatorial chemistry will deliver the goods by producing designer compounds aimed at unique molecular targets within the microbial cell. This may be so, but the new technology will have to improve on the record of microbial biochemistry, which, in the halcyon days of biochemical research of the 1940s1970 s, promised much in identifying vulnerable metabolic pathways peculiar to the microbial cell and came up with absolutely nothing of practical value. Similarly, the much vaunted attempts to manipulate cytokine responses have so far always fallen foul of the complex interactions that characterise them and much more needs to be learned before this avenue of treatment of sepsis becomes a realistic proposition [11]. Vaccines appear to offer a greater hope, as the new technologies do seem capable of advancing our capacity to prevent at least some of the infectious scourges of mankind $[12,13]$.

One of the most lamentable developments of the late 20th century that should concern all microbiologists has been the decline of medical microbiology as a clinically based discipline. The subject has been largely taken over - one might almost say hijacked - by the fashion for molecular biology. This is not to denigrate the work being pursued in the molecular field, which often provides stunning insights into biological problems and can already claim some successes, not least in the provision of new vaccines as already noted. However, the interface with the reality of infectious diseases in the community and the clinic, which used to be provided by medically qualified microbiologists who combined academic excellence with practical diagnostic expertise, is being systematically dismantled. Meanwhile, time devoted to microbiology in medical school curricula is being curtailed, and that which remains is often being delivered by molecular scientists who have never seen a patient. Reversing this trend is a priority for the new millennium if the training of young doctors in the problems of infection that they are going to encounter in their daily practice is not to be compromised.

Anton Chekhov in his short story $A$ Boring Story (from an Old Man's Notebook), written in 1889, puts into the mouth of his fictional narrator, a University Professor from the Medical Faculty: 'I should like to wake in a hundred years and take a look, even if only with one eye, at what has happened to science' [14]. Chekhov, a doctor himself, would be astonished at what has been accomplished in those 100 years, but would undoubtedly find much to disturb him as well. Who knows what awaits our great-grandchildren at the end of the next century?

DAVID GREENWOOD Division of Microbiology and Infectious Diseases, School of Clinical Laboratory Sciences, University Hospital, Queen's Medical Centre, Nottingham NG7 2UH (e-mail: david.greenwood@nottingham.ac.uk) 


\section{References}

1. Porter R. The greatest benefit to mankind. A medical history of humanity from antiqiuty to the present. London, HarperCollins. 1997.

2. Loudon I. Death in childbirth. An international study of maternal care and maternal mortality 1800-1850. Oxford, Clarendon Press. 1992.

3. Armstrong GL, Conn LA, Pinner RW. Trends in infectious disease mortality in the United States during the 20th century. JAMA 1999; 281: 61-66.

4. Mackenbach JP, Looman CWN. Secular trends of infectious disease mortality in the Netherlands, 1911-1978: quantitative estimates of changes coinciding with the introduction of antibiotics. Int $J$ Epidemiol 1988; 17: 618-624.

5. Behbehani AM. The smallpox story: life and death of an old disease. Microbiol Rev 1983; 47: 455-509.

6. Behbehani K. Candidate parasitic diseases. Bull World Health
Organ 1998; 76 Suppl 2: 64-67.

7. World Health Organization website. http://www.who.int/ aboutwho/en/preventing/diarrhoeal.htm

8. Cohen ML. Epidemiology of drug resistance: implications for a post-antimicrobial era. Science 1992; 257: 1050-1055.

9. Greenwood D. Resistance to antimicrobial agents: a personal view. J Med Microbiol 1998; 47: 751-755.

10. Kunin CM. Resistance to antimicrobial drugs - a worldwide calamity. Ann Intern Med 1993; 118: 557-561.

11. Baumgartner J-D, Calandra T. Treatment of sepsis: past and future avenues. Drugs 1999; 57: 127-132.

12. Kurstak E. Towards new vaccines and modern vaccinology: introductory remarks. Vaccine 1999; 17: 1583-1586.

13. Ellis RW. New technologies for making vaccines. Vaccine 1999; 17: 1596-1604.

14. Chekhov AP. Lady with lapdog and other stories (translated by David Magarshack). Penguin Books, Harmondsworth. 1964: 101. 